\title{
Impact of antiepileptic-drug treatment burden on health-care-resource utilization and costs
}

\author{
Krithika Rajagopalan' \\ Sean D Candrilli² \\ Mayank Ajmera²
}

'Sunovion Pharmaceuticals Inc, Marlborough, MA 0I752, USA; ${ }^{2}$ RTI

Health Solutions, Research Triangle

Park, NC 27709, USA
Correspondence: Krithika Rajagopalan Sunovion Pharmaceuticals Inc, 84 Waterford Drive, Marlborough, MA 01752 , USA

Tel +l 508787450 I

Email Krithika.Rajagopalan@sunovion.com
This article was published in the following Dove Press journal: ClinicoEconomics and Outcomes Research

Background: Complex titration requirements and dosing of antiepileptic drugs (AEDs) may pose a significant treatment burden for patients with epilepsy. This study evaluated health-careresource utilization (HCRU) rates and costs by treatment burden, defined as number of daily pills and dosing frequency, among managed-care enrollees with epilepsy who initiated AED monotherapy.

Methods: This retrospective longitudinal study examined administrative HC-claim data in patients aged $\geq 18$ years with two or more pharmacy claims for an AED and two or more medical claims for epilepsy or afebrile convulsion. The number of daily AED pills was estimated at index as the total number of pills dispensed divided by the days supplied, and categorized as more than zero/one, one/two, two/three, and more than three per day. AED-dosing frequency was measured at index and categorized as one, two, three, or four times daily. Postindex 12-month all-cause and epilepsy-related HCRU and costs were estimated using multivariable Poisson regression models and generalized linear models, respectively.

Results: Unadjusted total all-cause and epilepsy-related costs at 12 months postindex averaged US\$26,015 per person and US\$5,557 per person (2017 values), respectively. Adjusted all-cause and epilepsy-related costs were US $\$ 25,918$ per person and US $\$ 5,602$ per person, respectively. A pill burden of more than three a day was associated with a $6.7 \%$ increase in total annual $\mathrm{HC}$ costs compared with one pill/day. Patients receiving one/two, two/three, and more than three pills per day had $13.3 \%, 23.9 \%$, and $38.3 \%$ higher epilepsy-related costs, respectively, than those receiving one pill per day $(P<0.0001)$. Increase in dosing frequency was associated with greater total HCRU and higher costs, but only patients with twice-daily dosing had significantly higher epilepsy-related costs.

Conclusion: Findings from this study suggest that increased treatment burden is associated with greater HCRU and higher overall and epilepsy-related costs. Reducing treatment burden via selection of AED therapy with reduced pill numbers and dosing frequency should be considered to improve health and economic outcomes.

Keywords: antiepileptic drugs, health-care-resource utilization, treatment burden, epilepsyrelated costs

\section{Introduction}

Epilepsy is a chronic neurological disorder characterized by frequent seizures that affects $>3.4$ million people in the US and approximately 50 million worldwide. ${ }^{1,2}$ 
Approximately 150,000 new cases are diagnosed in the US each year. ${ }^{1}$ Epilepsy is not only associated with premature death. ${ }^{3,4}$ It can significantly impact patients' lives through an increased risk of fractures and injuries and higher incidence of headaches, sleep disturbances, and other somatic comorbidities. ${ }^{3-5}$ The cumulative effect of increased comorbidity and mortality risk and comorbidities from seizures also negatively impacts patients' health-related quality of life. ${ }^{4,5}$ As such, achieving seizure freedom remains the primary goal in the treatment and management of epilepsy.

Seizures are most commonly managed by the administration of antiepileptic drugs (AEDs). A variety of AEDs with a unique combination of mechanisms of action and pharmacokinetic profiles are available to treat patients, either as monotherapy or adjunctive therapy. Despite the available choice of AEDs, only about $50 \%$ of newly diagnosed patients with epilepsy achieve seizure control with their first AED. ${ }^{6}$ It is reported that an additional $10 \%$ of patients may switch to a second or third AED to achieve adequate seizure control, and a minority of patients require adjunct therapy with multiple AEDs. The remaining 30\% of patients do not achieve seizure control at all. ${ }^{6}$

Lack of seizure control in epilepsy patients is thought to occur for many reasons, some of which are treatment-related, including lack of therapeutic effect, intolerable side effects, and idiosyncratic reactions. ${ }^{6}$ Another potential reason for poor seizure control is nonadherence, due to either complex dose-optimizing procedures or frequent dosing that may be burdensome to patients. In other cases, the AED may be associated with a narrow therapeutic index and thus potentially require a slow titration to reduce toxicity while achieving treatment effect. ${ }^{7-11}$ Finally, for some AEDs, the regimens are intrinsically burdensome, even after achieving an optimal target dose, and may require multiple doses and/ or multiple pills per day to maintain steady-state plasma concentration. ${ }^{8,12}$ Therefore, it is plausible that the number of pills or doses per day may reduce treatment adherence and thus impair seizure control. ${ }^{12}$

Several studies have correlated nonadherence to AED treatment with increasing number of pills, dosing frequency, or treatment complexity. ${ }^{12-14}$ Research has also associated missed doses of AEDs with increased seizure frequency in epilepsy patients. ${ }^{12}$ Reduced adherence to AEDs and subsequent loss of seizure control are associated with increased health-care-resource utilization (HCRU) such as increased hospitalizations and emergency room (ER) visits, resulting in higher overall costs. ${ }^{15,16}$ While evidence suggests that nonadherence to AEDs may have an adverse impact on HCRU and costs, the potential impact of AED-treatment burden on HCRU and costs has not been widely explored in epilepsy. This study evaluated the impact of AED-treatment burden, defined as number of daily pills and dosing frequency on HCRU and costs in managed-care enrollees diagnosed with epilepsy who initiated monotherapy.

\section{Methods}

\section{Study design and data source}

This retrospective longitudinal study was conducted using managed HC-claim data from Quintiles IMS Health realworld data adjudicated claims (2006-2011), a commercially available source of administrative claim information covering more than 150 million unique patients across the US. ${ }^{17}$ The Quintiles IMS database represents information from every US metropolitan statistical area, and has an age and sex distribution representative of managed-care enrollment in the US. ${ }^{18}$

The database includes information on patient demographics and health-plan enrollment, primary and secondary diagnoses, hospitalizations, diagnostic testing, therapeutic procedures, prescription-drug use, and cost data according to managed-care reimbursement rates. ${ }^{18}$ Since claims from the database are deidentified and analyzed in aggregate, pursuant to the Health Insurance Portability and Accountability Act of 1996 and other regulations, institutional review-board review was not required for conducting this research.

\section{Patient selection}

Adult patients (aged 18-65 years) with two or more pharmacy claims for an AED (carbamazepine, gabapentin, lamotrigine, levetiracetam, oxcarbazepine, phenobarbital, phenytoin, primidone, pregabalin, tiagabine, topiramate, valproic acid, or zonisamide) on two distinct dates between January 1, 2006 and December 31, 2011 were included. Pharmacy and medical claims could occur anytime within the 5-year study period. All eligible patients were also required to have two or more medical claims (eg, inpatient, physician office, ER) on distinct dates with a primary or secondary diagnosis for epilepsy (ICD9-CM code 345.xx) or afebrile convulsions (ICD9-CM code 780.39) and have continuous data for $\geq 6$ months before and $\geq 12$ months after their index date (ie, follow-up period). Patients had 
to be naïve to AEDs to be entered into the study. The date of the first AED pharmacy claim was defined as the index date. Since the study was an analysis of patients on AED monotherapy, patients with more than one type of AED on the index date were excluded.

\section{Independent variables}

\section{Demographic and comorbidity characteristics}

Patient demographics, including age, sex, and geographic region, were included in the analysis. Additional preindex independent variables included "comorbidity burden", measured using Charlson Comorbidity Index (CCI) score. ${ }^{19,20}$

\section{Number of daily AED pills and dosing frequency}

The number of daily AED pills was estimated at index date as the total number of pills dispensed divided by days supplied, as recorded on the prescription claim. Number of daily pills was categorized as more than zero/one, one/two, two/ three, and more than three per day. AED-dosing frequency was measured at index as number of doses daily and categorized as one, two, three, or four times daily according to the US Food and Drug Administration-approved dosing frequency for each AED. We also calculated pill burden during the 12-month follow-up period by dividing total number of pills dispensed by days supplied. The results obtained from pill burden assessed over the 12-month period were comparable to those obtained from the index pill burden. Moreover, the direction of association or statistical significance did not change greatly for epilepsy-related HCRU, and thus we have elected to use index-date analysis in this report.

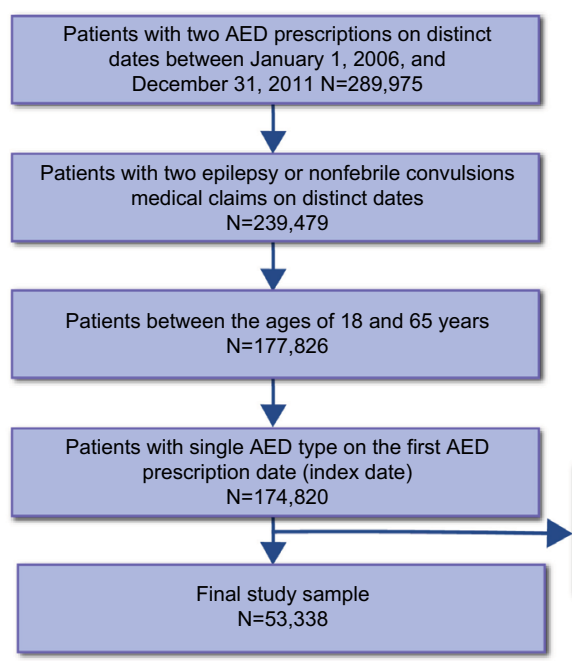

Patients excluded due to insufficient health plan enrollment (i.e., $<6$ and $<12$ months continuous enrollment before and after the index date $\mathrm{N}=121,482$

Figure I Patient selection.

Abbreviation: AED, antiepileptic drug.

\section{Dependent variables}

Postindex HCRU and costs

Postindex 12-month all-cause HCRU and costs were estimated individually as inpatient, ER, outpatient pharmacy, and physician office visits. Other outpatient services were assessed as a total. Similar postindex assessments were conducted on 12-month HCRU and costs for all epilepsyrelated claims, defined as a primary or secondary diagnosis for epilepsy (ICD9-CM code 345.xx), afebrile convulsions (ICD9-CM code 780.39), or a prescription for an AED. All patient-level costs were adjusted to 2017 US dollars using appropriate inflators from the medical care component of the US Consumer Price Index.

\section{Statistical analysis}

Descriptive analyses of all study measures were reported by index daily AED pills and dosing frequency, including mean, SD, median, and range for continuous variables and frequency distributions for categorical variables. Multivariable Poisson regression models assessed relationships among number of daily pills, dosing frequency, and annual rates of all-cause and epilepsy-related HCRU. Generalized linear models examined the relationship between index daily AED pills and $\mathrm{HC}$ costs incurred during the 12-month postindex period. All multivariable models were adjusted for potentially confounding variables, including patient demographics, baseline comorbidity burden, and preindex all-cause costs.

\section{Results}

A total of 53,338 patients met the study-eligibility criteria (Figure 1). Table $1 \mathrm{~A}$ and $1 \mathrm{~B}$ present patient characteristics at index date, by daily pill number and dosing frequency, respectively. 
Table I Patient demographics and clinical characteristics by AED daily pills $(\mathbf{A})$ and dose frequency at index date (B)

\begin{tabular}{|c|c|c|c|c|c|}
\hline \multicolumn{6}{|l|}{ A } \\
\hline & \multirow[b]{2}{*}{ All patients } & \multicolumn{4}{|c|}{ Index daily AED number of pills } \\
\hline & & $>0-I$ pill per day & $>I-2$ pills per day & $>2-3$ pills per day & $>3$ pills per day \\
\hline & $n=53,338$ & $\mathrm{n}=\mathbf{7 , 0 2 7}$ & $\mathrm{n}=20,068$ & $\mathrm{n}=|\mathbf{I}, \mathbf{0 7}|$ & $n=15,172$ \\
\hline \multicolumn{6}{|l|}{ Age at index date, years } \\
\hline Mean (SD) & $44.1(13.1)$ & $44.0(13.2)$ & $43.3(13.3)$ & $45.4(12.6)$ & $44.3(13.0)$ \\
\hline Median & 46 & 46 & 45 & 48 & 47 \\
\hline QI, Q3 & 34,55 & 34,55 & 33,54 & 37,56 & 35,55 \\
\hline \multicolumn{6}{|l|}{ Sex, n (\%) } \\
\hline Male & $23,064(43.2)$ & $2,585(36.8)$ & $8,133(40.5)$ & $4,768(43.1)$ & $7,578(49.4)$ \\
\hline Female & $30,274(56.8)$ & $4,442(63.2)$ & $1 \mathrm{I}, 935(59.5)$ & $6,303(56.9)$ & $7,594(50.1)$ \\
\hline \multicolumn{6}{|l|}{ Geographic region, $\mathbf{n}(\%)$} \\
\hline Northeast & II,298 (2I.2) & I,33I (I8.9) & $4,366(21.8)$ & $2,379(21.5)$ & $3,222(2 \mid .2)$ \\
\hline Midwest & $16,099(30.2)$ & $\mathrm{I}, 3 \mathrm{I} 4(\mathrm{I} 8.7)$ & $6,173(30.8)$ & $3,437(31.0)$ & $5,175(34.1)$ \\
\hline South & $19,507(36.6)$ & $2,215(31.5)$ & $7,874(39.2)$ & $4,214(38.1)$ & $5,204(34.3)$ \\
\hline West & $6,434(12.1)$ & $2,167(30.8)$ & $\mathrm{I}, 655(8.2)$ & $\mathrm{I}, 04 \mathrm{I}(9.4)$ & $\mathrm{I}, 57 \mathrm{I}(10.4)$ \\
\hline \multicolumn{6}{|c|}{ Health-plan type at index date, n (\%) } \\
\hline $\mathrm{HMO}$ & $8,024(15.0)$ & $668(9.5)$ & $3,031(15.1)$ & $\mathrm{I}, 784(\mathrm{I} 6 . \mathrm{I})$ & $2,54 I(16.7)$ \\
\hline PPO & $40,009(75.0)$ & $5,479(78.0)$ & $15,207(75.8)$ & $8,245(74.5)$ & $\mathrm{II}, 078(73.0)$ \\
\hline Other $^{\mathrm{a}}$ & $4,990(9.4)$ & $856(12.1)$ & $\mathrm{I}, 706(8.4)$ & $974(8.8)$ & $1,454(9.6)$ \\
\hline Unknown & $315(0.6)$ & $24(0.3)$ & $124(0.6)$ & $68(0.6)$ & $99(0.7)$ \\
\hline \multicolumn{6}{|c|}{ Payer type at index date, $\mathrm{n}(\%)$} \\
\hline Commercial & $34,493(64.7)$ & $5,161(73.4)$ & $12,752(63.5)$ & $6,917(62.5)$ & $9,663(63.7)$ \\
\hline Self-insured & $17,183(32.2)$ & $\mathrm{I}, 637(23.3)$ & $6,819(34.0)$ & $3,777(34.1)$ & $4,950(32.6)$ \\
\hline Medicare/Medicaid ${ }^{b}$ & $\mathrm{I}, 534(2.9)$ & $217(3.1)$ & $445(2.2)$ & $352(3.1)$ & $520(3.5)$ \\
\hline Unknown & $128(0.2)$ & $12(0.2)$ & $52(0.3)$ & $25(0.2)$ & $39(0.3)$ \\
\hline \multicolumn{6}{|l|}{ Preindex $\mathrm{CCl}$ score } \\
\hline Mean (SD) & $1.4(2.1)$ & $1.3(1.9)$ & $\mathrm{I} .5(2.2)$ & $1.4(2.1)$ & $\mathrm{I} .3(2.1)$ \\
\hline Median & 1.0 & 1.0 & 1.0 & 1.0 & 1.0 \\
\hline$(\mathrm{QI}, \mathrm{Q} 3)$ & $(0,2.0)$ & $(0,2.0)$ & $(0,2.0)$ & $(0,2.0)$ & $(0,2.0)$ \\
\hline $\begin{array}{l}\text { Preindex comorbid CCI } \\
\text { conditions }(\geq \mathbf{I}), \mathbf{n}(\%)^{c}\end{array}$ & $28,342(53.1)$ & $3,828(54.5)$ & $10,808(53.9)$ & $6,050(54.6)$ & $7,656(50.5)$ \\
\hline Hypertension & I3,553 (25.4) & $\mathrm{I}, 7 \mathrm{I} 4(24.4)$ & $5,226(26.0)$ & $3,004(27.1)$ & $3,609(23.8)$ \\
\hline Depression & $8,090(15.2)$ & $\mathrm{I}, 297(18.5)$ & $3,055(15.2)$ & $1,809(16.3)$ & $1,929(12.7)$ \\
\hline Cerebrovascular disease & $7,100(13.3)$ & $812(11.6)$ & $3,253(16.2)$ & $\mathrm{I}, 300(\mathrm{II} .7)$ & $\mathrm{I}, 735(\mathrm{II} .4)$ \\
\hline Chronic pulmonary disease & $5,65 I(10.6)$ & $709(10.1)$ & $2,072(10.3)$ & $1,317(11.9)$ & $1,553(10.2)$ \\
\hline $\begin{array}{l}\text { Diabetes without } \\
\text { complications }\end{array}$ & $5,244(9.8)$ & $734(10.4)$ & $\mathrm{I}, 899(9.5)$ & $\mathrm{I}, 168(10.6)$ & $\mathrm{I}, 443(9.5)$ \\
\hline Malignancy ${ }^{d}$ & $3,581(6.7)$ & $365(5.2)$ & $\mathrm{I}, 582(7.9)$ & $682(6.2)$ & $952(6.3)$ \\
\hline \multicolumn{6}{|l|}{ Preindex total costs, US\$ } \\
\hline Mean (SD) & $17,572(50,895)$ & $15,588(47,730)$ & $19,388(52,863)$ & $15,765(43,743)$ & $17,270(54,323)$ \\
\hline Median (QI, Q3) & $\begin{array}{l}4,37 \mid(1,442 \\
\mid 2,448)\end{array}$ & $\begin{array}{l}4,4 I \mid(1,535 \\
I I, 5 \mid 9)\end{array}$ & $\begin{array}{l}4,873(1,732 \\
13,795)\end{array}$ & $\begin{array}{l}4,286(1,320 \\
12,430)\end{array}$ & $\begin{array}{l}3,788(1,130 \\
11,144)\end{array}$ \\
\hline \multicolumn{6}{|l|}{ B } \\
\hline & & \multicolumn{4}{|c|}{ Index AED dose frequency } \\
\hline & All patients & Once daily & Twice daily & Thrice daily & Four times daily \\
\hline & $n=53,338$ & $n=5,974$ & $n=31,218$ & $n=16,102$ & $\mathrm{n}=\mathbf{4 4}$ \\
\hline \multicolumn{6}{|l|}{ Age at index date, years } \\
\hline Mean (SD) & $44.1(13.1)$ & $41.3(13.5)$ & $42.4(13.4)$ & $48.4(I I .2)$ & $36.7(14.9)$ \\
\hline Median & 46.0 & 42.0 & 44.0 & 50.0 & 31.0 \\
\hline$(\mathrm{Q} I, \mathrm{Q} 3)$ & $(34.0,55.0)$ & $(30.0,53.0)$ & $(32.0,54.0)$ & $(4 I .0,57.0)$ & $(22.5,52.5)$ \\
\hline \multicolumn{6}{|l|}{ Sex, n (\%) } \\
\hline Male & $23,064(43.2)$ & $2,85 I(47.7)$ & $12,440(39.8)$ & $7,752(48.1)$ & $21(47.7)$ \\
\hline Female & $30,274(56.8)$ & $3,123(52.3)$ & $18,778(60.2)$ & $8,350(51.9)$ & $23(52.3)$ \\
\hline \multicolumn{6}{|l|}{ Geographic region, $\mathbf{n}(\%)$} \\
\hline Northeast & $1 \mathrm{I}, 298(21.2)$ & $\mathrm{I}, 265(21.2)$ & $6,605(21.2)$ & $3,4 \mid 8(2 \mid .2)$ & $10(22.7)$ \\
\hline Midwest & $16,099(30.2)$ & $1,799(30.1)$ & $9,45 I(30.3)$ & $4,836(30.0)$ & $13(29.5)$ \\
\hline South & $19,507(36.6)$ & $2,129(35.6)$ & $\mathrm{II}, 5 \mathrm{I} 3(36.9)$ & $5,849(36.3)$ & $16(36.4)$ \\
\hline West & $6,434(12.1)$ & $78 I(13.1)$ & 3,649 (II.7) & $1,999(12.4)$ & $5(11.4)$ \\
\hline
\end{tabular}


Table I (Continued)

\begin{tabular}{|c|c|c|c|c|c|}
\hline & \multirow[b]{2}{*}{ All patients } & \multicolumn{4}{|c|}{ Index AED dose frequency } \\
\hline & & Once daily & Twice daily & Thrice daily & Four times daily \\
\hline & $n=53,338$ & $n=5,974$ & $n=31,218$ & $n=16,102$ & $n=44$ \\
\hline \multicolumn{6}{|c|}{ Health plan type at index date, n (\%) } \\
\hline $\mathrm{HMO}$ & $8,024(15.0)$ & $939(15.7)$ & $4,550(14.6)$ & $2,526(15.7)$ & $9(20.5)$ \\
\hline PPO & $40,009(75.0)$ & $4,396(73.6)$ & $23,553(75.4)$ & $12,030(74.7)$ & $30(68.2)$ \\
\hline Other $^{\mathrm{a}}$ & $4,990(9.4)$ & $606(10.2)$ & $2,918(9.3)$ & $\mathrm{I}, 46 \mathrm{I}(9 . \mathrm{I})$ & $5(I I .3)$ \\
\hline Unknown & $315(0.6)$ & $33(0.6)$ & $197(0.6)$ & $85(0.5)$ & 0 \\
\hline \multicolumn{6}{|c|}{ Payer type at index date, $n(\%)$} \\
\hline Commercial & $34,493(64.7)$ & $3,757(62.9)$ & $20,391(65.3)$ & $10,324(64.1)$ & $21(47.7)$ \\
\hline Self-insured & $17,183(32.2)$ & $1,978(33.1)$ & $10,037(32.2)$ & $5,151(32.0)$ & $17(38.6)$ \\
\hline Medicare/Medicaid ${ }^{b}$ & $\mathrm{I}, 534(2.9)$ & $222(3.7)$ & $712(2.3)$ & $594(3.6)$ & $6(13.6)$ \\
\hline Unknown & $128(0.2)$ & $17(0.3)$ & $78(0.2)$ & $33(0.2)$ & 0 \\
\hline \multicolumn{6}{|l|}{ Preindex $\mathrm{CCl}$ score } \\
\hline Mean (SD) & I.4 (2.I) & $1.0(1.7)$ & I.3 (2.I) & I.7 (2.3) & $\mathrm{I} .8(2.2)$ \\
\hline Median & 1.0 & 0 & 1.0 & 1.0 & 1.0 \\
\hline$(\mathrm{QI}, \mathrm{Q} 3)$ & $(0,2.0)$ & $(0,2.0)$ & $(0,2.0)$ & $(0,2.0)$ & $(0,2.0)$ \\
\hline $\begin{array}{l}\text { Preindex comorbid CCI } \\
\text { conditions (at least one), } \\
\text { n (\%) }\end{array}$ & $28,342(53.1)$ & $2,722(45.6)$ & $16,068(5 \mid .5)$ & $9,522(59.1)$ & $30(68.2)$ \\
\hline Hypertension & I3,553 (25.4) & $\mathrm{I}, 225(20.5)$ & $7,264(23.3)$ & $5,057(31.4)$ & $7(I 5.9)$ \\
\hline Depression & $8,090(15.2)$ & $855(14.3)$ & $4,540(14.5)$ & $2,689(16.7)$ & $6(13.6)$ \\
\hline Cerebrovascular disease & $7,100(13.3)$ & $50 \mathrm{I}(8.4)$ & 4,639 (I4.9) & $1,955(12.1)$ & $5(I I .4)$ \\
\hline Chronic pulmonary disease & $5,65 \mathrm{I}(10.6)$ & $517(8.7 \%)$ & $3,026(9.7)$ & $2,101(13.0)$ & $7(15.9)$ \\
\hline $\begin{array}{l}\text { Diabetes without } \\
\text { complications }\end{array}$ & $5,244(9.8)$ & $534(8.9)$ & $2,598(8.3)$ & $2,112(13.1)$ & 0 \\
\hline Malignancy $^{d}$ & $3,58 \mathrm{I}(6.7)$ & $213(3.6)$ & $2,259(7.2)$ & $1,106(6.9)$ & $3(6.8)$ \\
\hline
\end{tabular}

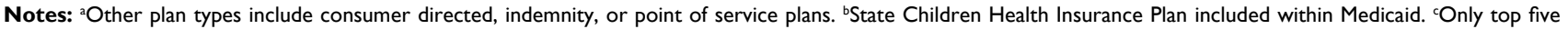
comorbidities are presented. ${ }^{~ A n y ~ m a l i g n a n c y, ~ i n c l u d i n g ~ l y m p h o m a ~ a n d ~ l e u k e m i a, ~ e x c e p t ~ m a l i g n a n t ~ n e o p l a s m ~ o f ~ s k i n . ~}$

Abbreviations: AED, antiepileptic drug; $\mathrm{CCl}$, Charlson Comorbidity Index; HMO, health-maintenance organization; PPO, preferred provider organization.

The mean age of the entire analysis population was 44.1 years, and $56.8 \%$ were female. Among the independent categories assessed, $37.6 \%$ of patients reported taking more than one or two pills a day and about $58.5 \%$ reported taking medications with twice-daily dosing (58.5\%) on the index date. While more than half the patients in the study were female, the proportion of females was greatest among those receiving more than zero/ one pills per day and lowest for those receiving more than three pills per day. Most patients were enrolled in commercial health plans. While baseline comorbidities were similar across daily pill categories, CCI scores were greatest among those with the highest dosing frequency per day.

\section{Total HCRU and costs for all patients}

All-cause and epilepsy-related HCRU and costs are presented in Table S1. Of all patients included in the analysis, $21.9 \%(\mathrm{n}=11,700)$ had at least one inpatient visit during the 12-month follow-up and approximately half these inpatient visits were epilepsy-related hospitalizations $(n=5,949)$. The unadjusted total annual all-cause cost averaged $\$ 26,015$ per person and unadjusted total annual epilepsy-related costs
$\$ 5,557$ per person. Adjusted all-cause and epilepsy-related costs were $\$ 25,918$ and $\$ 5,602$ per person, respectively.

\section{Association between number of daily pills and HCRU/costs}

Unadjusted rates and costs of all-cause and epilepsy-related HCRU were similar between patients on one pill per day and those on multiple pills per day (Table S1). Poisson regression models were used to assess significance after adjustment for confounding factors. Incidence-rate ratios for all-cause ER ranged from 0.944 to $1.000(P<0.05)$, for other outpatient HCRU from 1.001 to $1.020(P<0.0273)$, and were significantly greater for patients on multiple pills (Table S2). Incidence-rate ratios for epilepsy-related inpatient visits for patients taking more than one pill per day ranged 1.125-1.231 when compared with those on one pill per day $(P<0.005)$. The likelihood of all other epilepsy-related HCRU was also significantly greater in patients on multiple pills per day compared with those on one pill $(P<0.0001)$. Using the Poisson regression models evaluating significant effects on HCRU per patient during the 12-month follow-up period by 
AED pill burden during days with drugs on hand resulted in statistically significant differences in epilepsy-related inpatient and ER HCRU in patients on more than three pills/day.

Unadjusted total and epilepsy-related costs per patient among patients receiving more than zero/one, one/two, two/ three, and more than three pills per day are shown in Figure 2. After adjustment for confounders, annual total all-cause costs of patients on more than three pills per day were $6.7 \%$ higher than for those on one pill per day $(P=0.0002$; data not shown). Comparison of adjusted epilepsy-related costs showed that patients receiving more than one/two, more than two/three, and more than three pills per day had $13.3 \%, 23.9 \%$, and $38.3 \%$ higher costs, respectively, than those receiving one pill per day $(P<0.0001$; data not shown).

\section{Association between dosing frequency and HCRU/costs}

Unadjusted annual rates and costs of all-cause and epilepsyrelated HCRU were similar among patients dosed once daily and those receiving multiple doses daily (Table S3). Poisson regression models showed that thrice-daily dosing at index was associated with a significantly greater likelihood (each $P<0.0001$ ) of all-cause inpatient visits and ER visits (Table S4). Those with two or more daily doses were associated with increased usage of all-cause other outpatient services and physician office visits compared with once-daily dosing $(P<0.0001)$. Regression models suggested differences in the use of epilepsy-related ER services $(P<0.05)$ and other outpatient services $(P<0.005)$ with multiple daily dosing. An increase in epilepsy-related physician office visits showed statistical significance compared with once-daily dosing only with dosing twice or three times daily $(P<0.0001)$.

Unadjusted total and epilepsy-related costs per patient among patients with once-, twice-, thrice-, and four times daily dosing are presented in Figure 2. After adjustment for potential confounders, total costs were $14 \%, 40 \%$, and $62 \%$ higher among patients with twice-, thrice-, and four times daily dosing, respectively, compared with a once-daily regimen $(P<0.001$; data not shown). However, only patients with twice-daily dosing had significantly greater epilepsy-related costs compared with those with once-daily dosing $(P<0.0001$; data not shown).

\section{Discussion}

Overall, the findings from this analysis suggest that allcause and epilepsy-related HCRU and costs increased with increasing AED pill number and dosing frequency. ER and physician office visits and other outpatient resources were utilized more frequently when patients required more than two pills/day or dosing frequency exceeded once daily. Taking three or more pills per day was associated with a $6.7 \%$ increase in total all-cause annual HC costs compared with

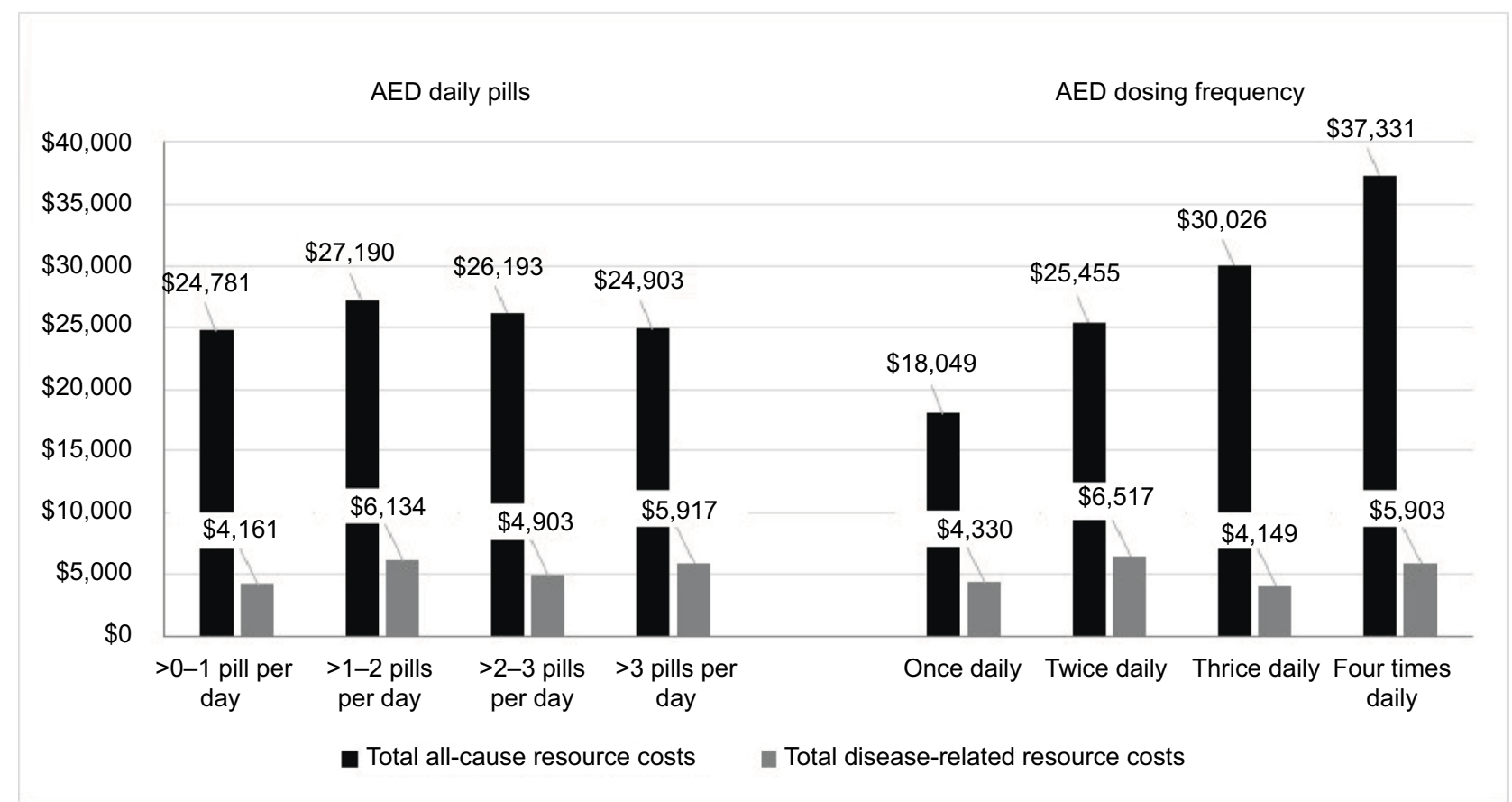

Figure 2 Unadjusted costs per patient by index daily AED pills and dosing frequency. Note: All costs expressed in US\$.

Abbreviation: AED, antiepileptic drug. 
taking one pill per day. Rates of epilepsy-related annual costs increased incrementally with increasing number of daily pills: a 38\% increase in epilepsy-related costs was associated with more than three AED pills/day. An increase in dosing frequency was associated with higher all-cause HCRU and total $\mathrm{HC}$ costs, but only patients with twice-daily dosing had significantly greater epilepsy-related costs.

An inverse relationship between dosing frequency and treatment adherence to AEDs has been reported in the literature. ${ }^{12-14}$ Therefore, it is plausible that the higher costs observed among patients with the greater treatment burden of a high number of pills and dosing frequency in this study are mediated through an impact on treatment adherence. Not surprisingly, in meta-analyses of prospective studies of various chronic diseases that included epilepsy, migraine, asthma, diabetes, cardiovascular diseases, and hypertension, patients have also shown increased adherence to once-daily dosing regimens compared with more frequent dosing. ${ }^{21}$ Cramer et al identified increased treatment burden as a predictor of nonadherence to AED treatment among patients with epilepsy. ${ }^{12}$ The study further showed that greater treatment burden increased the likelihood of seizure. Medications with dosing regimens involving less frequent dosing and fewer pills may improve patient adherence and thus treatment outcomes. Incorporation of once-daily dosing or slow-release formulations has been shown to lower $\mathrm{HC}$ costs and reduce HCRU in patients with chronic disease and epilepsy. ${ }^{22,23}$

We analyzed the data to determine medication adherence, defined as proportion of days covered (PDC). In addition, we assessed the association between dosing frequency and medication adherence ( $\mathrm{PDC}>0.8$ ) after controlling for patient characteristics. From our analyses, we found that patients on the thrice-daily dosage regimen were significantly less likely to have PDC $>0.8$ (OR 0.85, 95\% CI 0.79-0.90; $P<0.0001$ ) compared to those on the once-daily dosage regimen. These results are consistent with previous literature. ${ }^{12-14}$

Studies have shown consistently higher costs for patients with uncontrolled epilepsy (ranging from 2.1 to 10.6 times higher) than for patients with controlled epilepsy, and that increased costs were due to greater HCRU related to provider visits, ER visits, and hospitalizations. ${ }^{15,16,24-28}$ In a study aimed at understanding the association of nonadherence to AED therapy with $\mathrm{HCU}$ and costs, nonadherence was linked with a substantial increase in costs due to increased likelihood of ER visits and hospitalization and an increase in inpatient days. ${ }^{15}$ In that study, nonadherence was also associated with an increase in the annual likelihood of motor-vehicle accidents. While the relationship between treatment burden and adherence is not addressed in the current analysis and patient epilepsy control and severity were not defined, the greater economic impact observed with increased treatment burden in this study suggests a potential association with AED adherence and subsequent seizure control. Additional research is needed to understand this relationship.

Limitations of this retrospective observation analysis include possible selection bias, particularly for assessments by dosing frequency. While the inclusion criteria were imposed to obtain a uniform population, few patients were eligible for analysis in the highest dose-frequency category, which reduced the statistical power to detect significant change. In addition, the impact of confounding factors, such as seizure frequency and epilepsy severity, were not captured in the study data. Given that patients included in this study were required to have $\geq 6$ months of continuous enrollment prior to the first AED prescription, most likely had newly diagnosed epilepsy, which minimizes the potential effect of epilepsy severity on HCRU. Seizure type (eg, generalized clonic-tonic, partial-onset, status epilepticus) also confounds the analysis, as it may drive HCRU and costs. Patients with higher dosing frequency had higher CCI scores, due to hypertension, depression, cerebrovascular disease, chronic pulmonary disease, and diabetes, which may have contributed to higher all-cause HCRU and costs, but the influence of these comorbidities on epilepsy-related costs is unclear.

Also, we restricted patients to having taken AEDs as monotherapy on the index date, and pill burden and dosing frequency were measured as of the index date. A wider time frame would have restricted our patient population even more. Some patients may have had concomitant AED therapy postindex. In the current study, only $17 \%$ of patients took more than one AED during the 12-month follow-up period. Therefore, we believe that the results may not be substantially affected by this. Finally, the data may not represent the overall population of patients with epilepsy in the US, as the majority of patients in the present study received their $\mathrm{HC}$ through a commercial insurance plan. Additional research in populations from other payer sources is needed. Notwithstanding these limitations, to the authors' knowledge, the present analysis is the first study to define the effect of increased AED-treatment burden on HCRU and costs in patients with epilepsy.

\section{Conclusion}

Findings from the current study suggest that increased treatment burden, defined using pills/day and doses/day, is associated with greater risk of HCRU and higher overall and epilepsy-related costs. Reducing treatment burden via 
selection of AED therapy with lower pill numbers and dosing frequency may affect treatment adherence, and should thus be considered to improve both health and economic outcomes.

\section{Data availability}

All data generated or analyzed during this study are included in this published article and the Supplementary materials.

\section{Acknowledgments}

The authors thank Fulton Velez of Sunovion and Jennifer Korsnes of RTI Health Solutions for their involvement in study design and data analysis. The authors thank Ada AoBaslock, PhD and Patricia Segarini, PhD of Percolation Communications LLC for their editorial assistance. This study was sponsored by Sunovion Pharmaceuticals Inc. Sunovion participated in the study design, analysis and interpretation of data, and review and approval of the manuscript to submit for publication. Funding for manuscript development was provided by Sunovion Pharmaceuticals Inc.

\section{Author contributions}

All authors contributed to conception and design, data acquisition and interpretation, drafting the article or critically revising it for important intellectual content, and approved the final version to be published.

\section{Disclosure}

SDC and MA are employees of RTI Health Solutions, which received payment from Sunovion associated with the development and execution of this study. KR is an employee of Sunovion. The authors report no other conflicts of interest in this work.

\section{References}

1. Epilepsy Foundation. Epilepsy statistics. Landover, MD. Available from: http://www.epilepsy.com/learn/about-epilepsy-basics. Accessed September 25, 2017.

2. World Health Organization. Epilepsy: Fact Sheet. Geneva, Switzerland: World Health Organization; 2017. Available from: http://www.who.int/ news-room/fact-sheets/detail/epilepsy. Accessed September 24, 2018.

3. Beghi E. Addressing the burden of epilepsy: Many unmet needs. Pharmacol Res. 2016;107:79-84.

4. Keezer MR, Sisodiya SM, Sander JW. Comorbidities of epilepsy: current concepts and future perspectives. Lancet Neurol. 2016;15(1):106-115.

5. Gaitatzis A, Sisodiya SM, Sander JW. The somatic comorbidity of epilepsy: a weighty but often unrecognized burden. Epilepsia. 2012;53(8):1282-1293.

6. Kwan P, Brodie MJ. Early identification of refractory epilepsy. N Engl J Med. 2000;342(5):314-319.

7. Schmitz B, Montouris G, Schäuble B, Caleo S. Assessing the unmet treatment need in partial-onset epilepsy: looking beyond seizure control. Epilepsia. 2010;51(11):2231-2240.
8. Schmidt D, Schachter SC. Drug treatment of epilepsy in adults. BMJ. 2014;348:g254.

9. Biton V, Edwards KR, Montouris GD, et al. Topiramate titration and tolerability. Ann Pharmacother. 2001;35(2):173-179.

10. Biton V, Gil-Nagel A, Brodie MJ, Derossett SE, Nohria V. Safety and tolerability of different titration rates of retigabine (ezogabine) in patients with partial-onset seizures. Epilepsy Res. 2013;107(1-2): $138-145$.

11. Greenberg RG, Melloni C, Wu H, et al. Therapeutic Index estimation of antiepileptic drugs: a systematic literature review approach. Clin Neuropharmacol. 2016;39(5):232-240.

12. Cramer JA, Glassman M, Rienzi V. The relationship between poor medication compliance and seizures. Epilepsy Behav. 2002;3(4):338-342.

13. Brodtkorb E, Samsonsen C, Sund JK, Bråthen G, Helde G, Reimers A. Treatment non-adherence in pseudo-refractory epilepsy. Epilepsy Res. 2016;122:1-6.

14. O' Rourke G, O'Brien JJ. Identifying the barriers to antiepileptic drug adherence among adults with epilepsy. Seizure. 2017;45:160-168.

15. Davis KL, Candrilli SD, Edin HM. Prevalence and cost of nonadherence with antiepileptic drugs in an adult managed care population. Epilepsia. 2008;49(3):446-454.

16. Faught RE, Weiner JR, Guérin A, Cunnington MC, Duh MS. Impact of nonadherence to antiepileptic drugs on health care utilization and costs: findings from the RANSOM study. Epilepsia. 2009;50(3):501-509.

17. IMS Health Inc. IMS LifeLink PharMetrics Plus - U. S. Alexandria, VA: 2012. Available from: http://www.imstestarea.com/heor_emailer/ IMS_Lifelink_PHX_1012.pdf. Accessed September 24, 2018.

18. Bridge to Data DL. QuintilesIMS Real-World Data Adjudicated Claims: USA [QuintilesIMS PharMetrics Plus]. Available from: https://www. bridgetodata.org/node/824. Accessed October 11, 2017.

19. Charlson ME, Charlson RE, Peterson JC, Marinopoulos SS, Briggs WM, Hollenberg JP. The Charlson comorbidity index is adapted to predict costs of chronic disease in primary care patients. J Clin Epidemiol. 2008;61(12):1234-1240.

20. Deyo RA, Cherkin DC, Ciol MA. Adapting a clinical comorbidity index for use with ICD-9-CM administrative databases. J Clin Epidemiol. 1992;45(6):613-619.

21. Coleman CI, Limone B, Sobieraj DM, et al. Dosing frequency and medication adherence in chronic disease. J Manag Care Pharm. 2012;18(7):527-539.

22. Cohen CJ, Meyers JL, Davis KL. Association between daily antiretroviral pill burden and treatment adherence, hospitalisation risk, and other healthcare utilisation and costs in a US medicaid population with HIV. BMJ Open. 2013;3(8):e003028.

23. Richter A, Anton SF, Anton SE, Koch P, Dennett SL. The impact of reducing dose frequency on health outcomes. Clin Ther. 2003;25(8):2307-2335.

24. Begley CE, Durgin TL. The direct cost of epilepsy in the United States: A systematic review of estimates. Epilepsia. 2015;56(9):1376-1387.

25. Gupta S, Kwan P, Faught E, Tsong W, Forsythe A, Ryvlin P. Understanding the burden of idiopathic generalized epilepsy in the United States, Europe, and Brazil: An analysis from the National Health and Wellness Survey. Epilepsy Behav. 2016;55:146-156.

26. Hovinga CA, Asato MR, Manjunath R, et al. Association of nonadherence to antiepileptic drugs and seizures, quality of life, and productivity: survey of patients with epilepsy and physicians. Epilepsy Behav. 2008;13(2):316-322.

27. Samsonsen C, Reimers A, Bråthen G, Helde G, Brodtkorb E. Nonadherence to treatment causing acute hospitalizations in people with epilepsy: an observational, prospective study. Epilepsia. 2014;55(11): e125-e128.

28. Divino V, Petrilla AA, Bollu V, Velez F, Ettinger A, Makin C. Clinical and economic burden of breakthrough seizures. Epilepsy Behav. 2015;51:40-47. 
ClinicoEconomics and Outcomes Research is an international, peerreviewed open-access journal focusing on health technology assessment, pharmacoeconomics and outcomes research in the areas of diagnosis, medical devices, and clinical, surgical and pharmacological intervention. The economic impact of health policy and health systems organization also constitute important areas of coverage. The manuscript management system is completely online and includes a very quick and fair peer-review system, which is all easy to use. Visit http://www.dovepress.com/testimonials.php to read real quotes from published authors.

Submit your manuscript here: https://www.dovepress.com/clinicoeconomics-and-outcomes-research-journal 